\title{
Pre-positioning inventory and service outsourcing of relief material supply chain
}

\author{
Xin Yao ${ }^{\text {ab }}$, Ruting Huang ${ }^{\mathrm{a}}$, Malin Song ${ }^{*, \mathrm{c}}$, Nishikant Mishra ${ }^{\mathrm{d}}$ \\ ${ }^{a}$ China Center for Energy Economics Research, School of Economics, Xiamen \\ University, Xiamen, China; \\ ${ }^{\text {b} C o l l a b o r a t i v e ~ I n n o v a t i o n ~ C e n t e r ~ f o r ~ E n e r g y ~ E c o n o m i c s ~ a n d ~ E n e r g y ~ P o l i c y, ~ X i a m e n ~}$ \\ University, Xiamen, China; \\ 'School of Statistics and Applied Mathematics, Anhui University of Finance and \\ Economics, Bengbu, China; \\ ${ }^{\mathrm{d}}$ Hull Business School, University of Hull, UK.
}

\begin{abstract}
Service outsourcing is very common in a commercial supply chain, and in humanitarian relief area the transportation service is usually outsourced. To practice relief supply more effectively, it seems essential to enlarge outsourcing from shipping to more areas, and private enterprises could play a vital role. This paper examines the optimal pre-disaster order quantity of a certain relief commodity, based on a two-stage coordinated approach. Our findings show that the delay cost, shortage penalty cost, risk of supply shortage, salvage value, expected perishable rate, unit inventory cost and reactive price have significant impacts on the optimal amount of propositioned inventory. Moreover, the outsourcing strategies differ by types of relief commodities. For perishable supplies, proactive or reactive outsourcing would improve the benefits of buyer and supplier simultaneously. As for imperishable supplies, it is better to combine proactive insourcing approach and reactive outsourcing strategy. In view of some supplies whose monitoring cost is high, the insourcing approach is much better than outsourcing approach.
\end{abstract}

Key words: Operations management; Statistical methods; Optimization, Relief material supply chain; Service outsourcing.

${ }^{*}$ Corresponding author. No.962, Caoshan Road, Bengbu City, Anhui Province, P.R.C. 233030. E-mail: songmartin@163.com, Tel: +86 15805521822, Fax: +86 05523171212. 
This is an Accepted Manuscript of an article published by Taylor \& Francis in International Journal of Production Research on 19 July 2018, available online: http://www.tandfonline.com/10.1080/00207543.2018.1495853.

\section{Introduction}

Disasters, natural or man-made, have occurred more frequently in recent years, as well as the casualties (Nagurney et al. 2011; Day 2014). As shown in Fig. 1, about 18 thousand people were killed in the top 10 natural disaster by number of deaths in 2015 (UNISDR 2016). In addition, more than 200 million people are affected by natural disasters annually (Duran et al. 2011) and survival of the victims relies much on the humanitarian assistance provided by government or not-for-profit organizations (NPOs), such as Federal Emergency Management Agency (FEMA) and the Red Cross (Kunz et al. 2014).

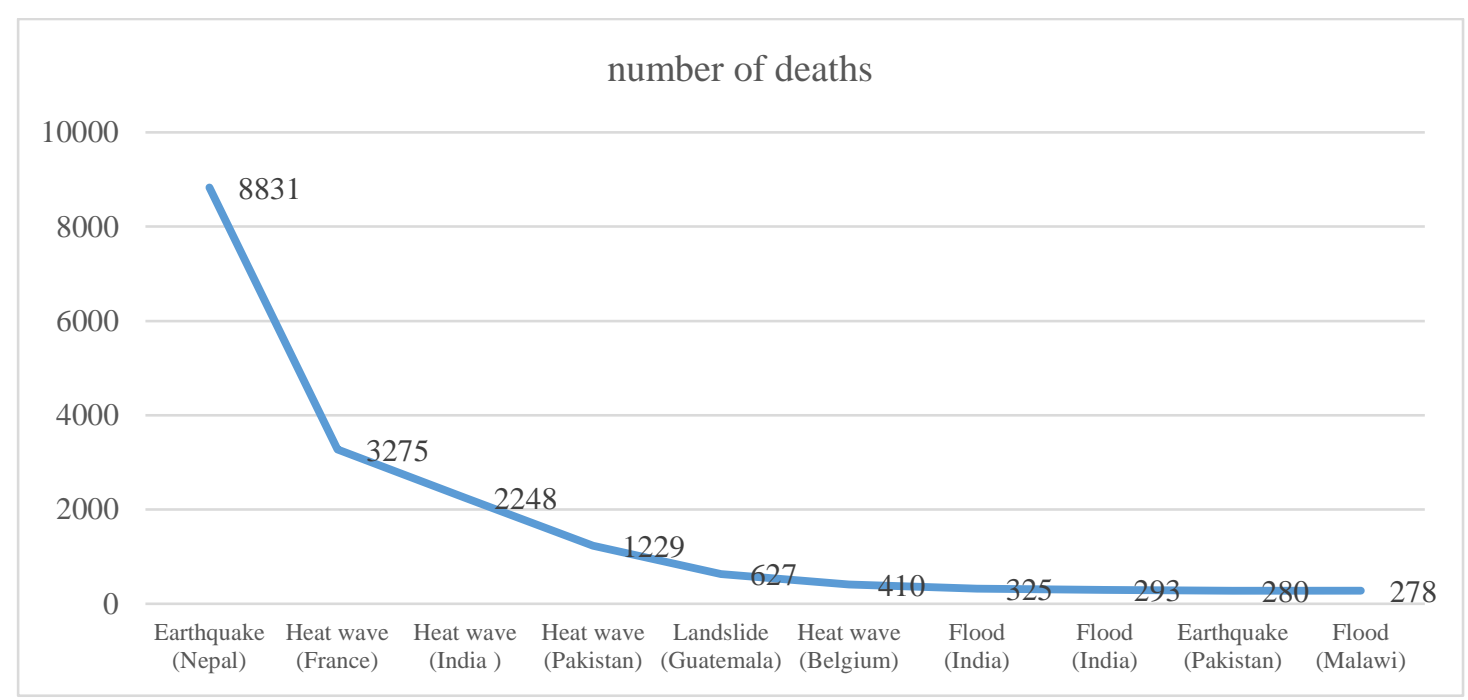

Figure 1. The top 10 natural disasters by number of deaths in 2015

Humanitarian operations management (HOM) refers to those operations to help individuals deal with disasters or human sufferings (Wang et al. 2015). The objective of relief supply is to provide humanitarian assistance to areas affected by large-emergencies, so as to minimize suffering or even death (Beamon and Balcik 2008; Balcik and Beamon 2008). In humanitarian actions, shortages or delivery delays may cause serious losses, and therefore efficient and effective logistics is a key factor (Beamon and Balcik 2008; Da Cosat et al. 2012; Naor et al. 2017). Global environmental problems have become more serious (Chavan 2017). Occurrence of various disasters is expected to increase by times in the next fifty years, due to environmental degradation and other factors (Thomas and Kopczak 2005). Thus, relief material supply chain management has received increased interest and focus (Ransikarbum and Mason 2014; Manopiniwes and Irohara 2016).

The responses against a disaster or disruption can be typically divided into four 
This is an Accepted Manuscript of an article published by Taylor \& Francis in International Journal of Production Research on 19 July 2018, available online: http://www.tandfonline.com/10.1080/00207543.2018.1495853.

phases: mitigation, preparation, immediate response and reconstruction (Lodree et al. 2012, Iakovou et al. 2014; Ivanov et al. 2014). An integrated approach to manage disasters comprises both proactive decisions and reactive approaches (Lin et al. 2008). Proactive decisions provide certain protections before a disaster occurs and reactive approach mainly focuses on adjusting supply chain processes in the presence of unexpected events (Ivanov et al. 2016; Dolgui et al. 2017).

Due to uncertainty, all needed relief supplies should be stored in advance to meet an emergency (Yadavalli 2015). Based on their characteristics, the critical items can be divided into two categories, non-perishable commodities (i.e., tent, clothing, blanket, non-perishable food, etc.) and perishable products, for instance, blood products, packed milk, medical commodities, etc. (Rezaei-Malek et al. 2016). Governments or NPOs are the purchasers of disaster reliefs, and large retailers such as Wal-Mart or Home Depot are the major suppliers. Governments or NPOs purchase critical relief materials from big retailers, store in advance and distribute them to the victims. FEMA and other government agencies were heavily criticized by the press and scholars for their failures in the 2005 Hurricane Katrina, while Wal-Mart and other private retailers were widely praised for being effective in providing disaster reliefs (Holguín-Veras 2007; Horwitz 2009). Governments and NPOs are well experienced in humanitarian relief rather than logistic management while large retailers are good at dealing with daily logistics problems.

We live in an age of outsourcing (Grossman and Helpman 2005). Service outsourcing is very common in a commercial supply chain. As for humanitarian relief, the transportation service has usually been outsourced. Large retailers, with enough inventory capacity and high turnover rate, are more expertized than governments and NPOs in terms of logistic management. Relief and commercial supply chain have some similarities, while there exist more differences (Kovács and Spens 2007; Wang et al. 2015). The differences between them may introduce some new issues worth of studying (Wang et al. 2015). The one that we want to analyze focuses on outsourcing strategy in relief material supply chain.

Relief material management is confronted with a dilemma (Wang et al. 2014). In proactive decisions, the prepositioned inventory can be obtained immediately after disaster strikes, with a low price. While, a large scale of pre-disaster inventory can be risky and costly since the demand is uncertain and the assets may be underutilized (Beamon and Kotleba 2006). Real-time response can reduce the loss caused by 
This is an Accepted Manuscript of an article published by Taylor \& Francis in International Journal of Production Research on 19 July 2018, available online: http://www.tandfonline.com/10.1080/00207543.2018.1495853.

uncertainty, while its shortcoming is the possible unavailability and high unit cost (Chakravarty 2014; Wang et al. 2014). In practice, purchasers often keep a certain amount of relief supplies in advance and trigger the real-time procurement once a disaster occurs (Chakravarty 2014).

Taking China for example, disasters happen frequently in recent years and China proposed to build a more complete relief material reserve network. Chinese government and NPOs play a leading role in disaster relief inventory. Some problems, however, still remain, such as poor way of inventory, limited variety and so on. This paper tries to solve this problem by introducing outsourcing into relief material supply chain. To enlarge outsourcing from shipping to more areas may contribute to more efficient relief material management, and private enterprises should play a vital role (Wang et al. 2016).

Therefore, we analyze the optimal pre-disaster inventory of certain relief commodities and compare the social efficiency between the insourcing and outsourcing approaches. The reminder of this paper is organized as follows. Section 2 presents a review of related literature. Section 3 describes the model and section 4 provides an analysis on a benchmarking case with insourcing approach. In section 5 , the outsourcing approach is compared. Section 6 concludes.

\section{Literature review}

In modern organizations, logistics management involves decision making for the complete distribution of goods or services, with a view to minimize cost and maximize efficiency. It is common for a company to outsource the function and buy logistics service in today’s business environment (Lieb and Randall 1997; Razzaque and Sheng 1998). Third party logistics is to get the right products to right places with right prices under the help of outsiders (Wei 2000). Through outsourcing other activities, enterprises can improve logistic efficiency, concentrate on their competencies and be more competitive. During recent decades, logistics outsourcing has been one of the top management agenda (Gadde and Hulthén, 2009) and has been widely studied in the field of commercial supply chain (Hong et al. 2004; Bottani and Rizzi 2006; Yang et al. 2016; König and Spinler 2016; Hansen et al. 2016). Sohail and Sohal (2003) examine the use of third party logistics in Malaysia and find that most of the users have largely seen positive development within organizations. Hsiao et al. 
This is an Accepted Manuscript of an article published by Taylor \& Francis in International Journal of Production Research on 19 July 2018, available online: http://www.tandfonline.com/10.1080/00207543.2018.1495853.

(2010) examine whether different logistics outsourcing activities leads to differences in logistic service performance. They find that the relationship between levels of outsourcing, performance and supply chain characteristic is complex.

Humanitarian relief chain shares some similar aspects with commercial supply chain, while some key areas are different. These features include the uncertain and dynamic environment and unique management principles in humanitarian relief chain operation (Day and Melnyk 2012). Note that, consumers of relief supplies are victims affected by large-emergencies and they are not traditional consumers. However, the frequency and scale of disasters tend to increase, more effective disaster relief services are needed.

Outsourcing in the field of humanitarian supply chain has also attracted some attention. Cottam et al. (2004) study the role of trucks outsourcing in the famine in Ethiopia in 2000 and find that outsourcing has both advantages and disadvantages. Carbonnier (2006) discusses the various parties involved in armed conflicts, especially those of private enterprises, and highlights that it is essential to better grasp the potential opportunities and risk related to privatization and outsourcing so as to provide effective assistance. In case of critical needs (e.g. medicine, food, water, vaccines etc.), Anna Nagurney et al. (2011) consider the design of supply chain networks and investigate whether the product should be produced in-house or be outsourced. Wang and Huang (2014) compare three disaster relief approaches which include traditional relief approach, transportation service outsourcing approach and inventory and transportation service outsourcing approach. They find that the efficiency of a relief supply chain could be improved by the logistic service outsourcing. Gil and Mcneil (2015) study the levels of outsourcing among the actors of the humanitarian response system to aid those, which are influenced by natural disasters or the armed conflict in Colombia. Wang et al. (2016) classify a relief supply chain into four types and the critical relief commodities into two categories as imperishable and perishable. They advocate that different strategies should be taken as the situation differs.

Relief material management is an important part of relief supply chain and has attracted much attention recently (Yang et al. 2014). For example, Barbarosoğlu and Arda (2004) propose a two-stage stochastic programming model to solve the response problem of distribution of vital first-aid commodities. Cruzcantillo and Saleh (2014) build a system dynamic model for the forecasting, prioritization and distribution of 
This is an Accepted Manuscript of an article published by Taylor \& Francis in International Journal of Production Research on 19 July 2018, available online: http://www.tandfonline.com/10.1080/00207543.2018.1495853.

critical relief supplies in case of a hurricane event. Some scholars have also introduced the option contract mechanism into the relief material management. Liang et al. (2012) apply the supply chain management mothed into relief material management to build an option pricing model. Wang et al. (2015) find that an option contract is superior to instant-purchasing. To the best of our knowledge, the existing literature focused on outsourcing in relief material supply chain is fairly inadequate.

Based on Wang et al. (2016), a two-stage coordinated approach model is built. There are some differences in these two papers. Firstly, what we want to discuss is the optimal prepositioned quantity of a certain good and the factors influencing the optimal quantity. In real disaster relief supply, it always has to combine both proactive decisions and real-time approach (Chakravarty, 2011; Wang et al. 2016). Thus, this paper considers the optimal stock quantity in a two-stage approach model which includes ex ante inventory and real-time acquisition. Moreover, the perishable rate may be a stochastic variable instead of being a constant, which depends on humidity and other effects. Finally, outsourcing has its perils and merits at the same. If the quality of some essential items is difficult to be supervised, the monitoring cost would be high. The relief material supply chain would be impacted by this inevitably. Taking different levels of monitoring cost into consideration, different response methods are analyzed to cope with different cases.

\section{Model description}

In this paper, we consider two stages for disaster relief, proactive decisions and real-time response after the disaster. In the first stage, the proactive inventory amount $Q_{i}$ of good $i$ is decided before disasters. And in the second stage, after the disaster has struck the relief provider should decide the optimal amount $q_{i}$ of good $i$ which is delivered to the affected location after demand realization. The demand for good $i$ is a stochastic variable $\mathrm{X}(x \geq 0)$. The probability density and cumulative distribution functions are $f(x)$ and $F(x)$ respectively. However, reactive approach involves supply risk and we assume that the probability of demand being satisfied is $\kappa(0 \leq \kappa \leq 1)$. In other words, the risk of supply shortage is $1-\kappa$. As it is known, the supply shortage may lead to serious suffering and even death. Therefore the unit shortage penalty cost is defined as $d_{i}$. For simplicity and analytical tractability, we 
This is an Accepted Manuscript of an article published by Taylor \& Francis in International Journal of Production Research on 19 July 2018, available online: http://www.tandfonline.com/10.1080/00207543.2018.1495853.

assume that $q_{i}$ equals to $\max \left(x-Q_{i}, 0\right)$. Similar assumptions can be found in Wang et al. (2015). After the disaster has struck, the prepositioned inventory $Q_{i}$ can be available as soon as possible while it takes some time for additional supplies $q_{i}$ to be delivered. Delays in receiving supplies will cause some social cost (Chakravarty 2014). Thus we assume that the social value for unit of $Q_{i}$ is $v_{i}^{0}$ and the unit value attained from $q_{i}$ is expressed as $v_{i}^{1}$, where $v_{i}^{0}$ is larger than $v_{i}^{1}$. In addition, we assume that the social value for unit of good $i$ is larger than the cost.

The wholesale price for $Q_{i}$ is assumed as $w_{i}$ and the retail price for $q_{i}$ is $p_{i}$, the cost of prepositioned relief supplies is $c_{i}^{p}$, the unit cost for real-time relief supplies is $c_{i}^{r}$ and salvage value of unused supplies is $s_{i}$. The relationship between them is expressed as $p_{i}>w_{i}>c_{i}^{r}>c_{i}^{p}>s_{i}$. The unit inventory and distribution costs are denoted as $I_{i}$ and $t_{i}$ respectively. Product $i$ perishes with ratio $\eta_{i}\left(0 \leq \eta_{i} \leq 1\right)$, which is assumed to be a stochastic variable. The probability density and cumulative distribution functions are $g\left(\eta_{i}\right)$ and $G\left(\eta_{i}\right)$ respectively.

The relief providers can choose between insourcing and outsourcing approaches. When outsourcing, the buyers can also choose between proactive decision and real-time response. When proactive outsourcing approach is taken, we assume that the relief providers pay $w_{i}^{\text {out }}$ for one unit of good $i$ where the relief material is stored and distributed by the third-party private enterprises. When reactive outsourcing strategy is taken, it is assumed that good $i$ is distributed by the third-party and the relief provider pay $p_{i}^{\text {out }}$ for one unit after a disaster has struck. The unit inventory and shipping cost for the private enterprises are $I_{i}^{\text {out }}$ and $t_{i}^{\text {out }}$ respectively, and the unit value attained from $q_{i}$ is expressed as $v_{i}^{2}$. Since the private enterprises has more logistic expertise than the government or NGOs, we assume that $v_{i}^{1}<v_{i}^{2}<v_{i}^{0}$, $I_{i}^{\text {out }}<I_{i}$, and $t_{i}^{\text {out }}<t_{i}$. Besides, to ensure the efficiency of outsourcing, there is some monitoring cost which is defined as $\beta_{i}$. 


\section{Basic model}

\subsection{A basic model with insourcing approach}

In this scenario, the government or NGOs purchase certain amount of relief materials from suppliers and provide inventory and distribution themselves. In the first stage, the purchaser decides the optimal amount $Q_{i}$ of item $i$ to be stored in the warehouse and in the second stage triggers the real-time response after a disaster strikes. As mentioned above, in the second stage all demand is satisfied with the probability $\kappa$ and we have $q_{i}=\max \left(x-Q_{i}, 0\right)$. Before the disaster, purchaser has sufficient time to bargain with suppliers and thus can purchase good $i$ with a relatively low unit price, which is $w_{i}$. Once real-time procurement triggers, the price the purchaser pays for one unit of item $i$ is the retail price $p_{i}$. As for the supplier, with sufficient time, the cost of the prepositioned relief supplies is $c_{i}^{p}$ and the cost for real-time relief supplies is $c_{i}^{r}$.

Thus the buyer's expected profit is expressed as follows.

$$
\begin{aligned}
\max _{Q_{i}} E(\pi) & =E\left[v_{i}^{0} \min \left(x, Q_{i}\right)+\kappa v_{i}^{1} \max \left(x-Q_{i}, 0\right)-(1-\kappa) d_{i} \max \left(x-Q_{i}, 0\right)\right. \\
& \left.+s_{i} \max \left(Q_{i}-x, 0\right)-\left(w_{i}+t_{i}+I_{i}+w_{i} \eta_{i}\right) Q_{i}-\kappa\left(p_{i}+t_{i}\right) \max \left(x-Q_{i}, 0\right)\right]
\end{aligned}
$$

Where the first two terms are the expected values of victims, the third term is the social cost for shortage penalty, the fourth term is the expected value from salvaging unused materials, the fifth term is cost of proactive inventory and the sixth term is the expected cost for real-time deliveries. The unit cost for $Q_{i}$ is $\left[w_{i}+t_{i}+I_{i}+w_{i} E\left(\eta_{i}\right)\right]$, where $w_{i}$ is the price paid to the supplier, $t_{i}$ is shipping cost, $I_{i}$ is inventory cost and $w_{i} E\left(\eta_{i}\right)$ is expected cost caused by deterioration. Without shortage, the unit cost for $q_{i}$ is expressed as $\left(p_{i}+t_{i}\right)$.

After some transformation, we can get

$$
\begin{aligned}
\max _{Q_{i}} E(\pi)= & {\left[-v_{i}^{0}+\kappa v_{i}^{1}-(1-\kappa) d_{i}+s_{i}-\kappa\left(p_{i}+t_{i}\right)\right] \int_{0}^{Q_{i}} F(x) d x+\left[\kappa v_{i}^{1}-(1-\kappa) d_{i}-\kappa\left(p_{i}+t_{i}\right)\right] E(x) } \\
& +\left\{v_{i}^{0}-\kappa v_{i}^{1}+(1-\kappa) d_{i}-\left[w_{i}+t_{i}+I_{i}+w_{i} E\left(\eta_{i}\right)\right]+\kappa\left(p_{i}+t_{i}\right)\right\} Q_{i}
\end{aligned}
$$

The goal of the purchaser is to maximize the expected social value by deciding the optimal amount of $Q_{i}$. The first order condition is: 
This is an Accepted Manuscript of an article published by Taylor \& Francis in International Journal of Production Research on 19 July 2018, available online: http://www.tandfonline.com/10.1080/00207543.2018.1495853.

$$
\begin{aligned}
\frac{\partial E\left[\pi\left(Q_{i}\right)\right]}{\partial Q_{i}} & =\left[-v_{i}^{0}+\kappa v_{i}^{1}-(1-\kappa) d_{i}+s_{i}-\kappa\left(p_{i}+t_{i}\right)\right] F\left(Q_{i}\right) \\
& +\left\{v_{i}^{0}-\kappa v_{i}^{1}+(1-\kappa) d_{i}-\left[w_{i}+t_{i}+I_{i}+w_{i} E\left(\eta_{i}\right)\right]+\kappa\left(p_{i}+t_{i}\right)\right\}=0
\end{aligned}
$$

The second order derivative of $E\left[\pi\left(Q_{i}\right)\right]$ with respective to $Q_{i}$ is expressed as follows:

$$
\frac{\partial^{2} E\left[\pi\left(Q_{i}\right)\right]}{\partial Q_{i}^{2}}=\left[-v_{i}^{0}+\kappa v_{i}^{1}-(1-\kappa) d_{i}+s_{i}-\kappa\left(p_{i}+t_{i}\right)\right] f\left(Q_{i}\right)
$$

Based on the assumption, we have $-\left[v_{i}^{0}-\kappa v_{i}^{1}+(1-\kappa) d_{i}-s_{i}+\kappa\left(p_{i}+t_{i}\right)\right]<0$. And we can obtain $\frac{\partial^{2} E\left[\pi\left(Q_{i}\right)\right]}{\partial Q_{i}^{2}}<0$. The first-order condition works. Denote $\gamma_{i}=v_{i}^{0}-\kappa v_{i}^{1}+(1-\kappa) d_{i}$, which can represent the cost of delay and shortage to a certain degree. The optimal stock quantity $Q_{i}^{*}$ is given as:

$$
Q_{i}^{*}=F^{-1}\left(\frac{\gamma_{i}+\kappa \theta_{r}-\theta_{p}}{\gamma_{i}+\kappa \theta_{r}-s_{i}}\right)
$$

Where $\theta_{p}=w_{i}+t_{i}+I_{i}+w_{i} E\left(\eta_{i}\right)$ and $\theta_{r}=p_{i}+t_{i}$.

Proposition 1. When and only when the difference between the prepositioned cost and the real-time cost is lower than the expected delay and shortage cost, the purchasers would choose to store relief supplies in advance, to enable a quick response to disasters; otherwise, it is much better to take reactive approach.

$$
Q_{i}^{*}= \begin{cases}0 & \text { if } \theta_{p}-\kappa \theta_{r} \geq \gamma_{i} \\ F^{-1}\left(\frac{\gamma_{i}+\kappa \theta_{r}-\theta_{p}}{\gamma_{i}+\kappa \theta_{r}-s_{i}}\right) & \text { if } \theta_{p}-\kappa \theta_{r}<\gamma_{i}\end{cases}
$$

Since this paper tries to study the optimal stock quantity of a certain relief commodity ahead of time and compare the social efficiency with and without outsourcing, we assume $\theta_{p}-\kappa \theta_{r}<\gamma_{i}$. The expected social value is:

$$
\begin{aligned}
\mathrm{V}\left(Q_{i}^{*}\right) & =\left[-v_{i}^{0}+\kappa v_{i}^{1}-(1-\kappa) d_{i}+s_{i}-\kappa\left(p_{i}+t_{i}\right)\right] \int_{0}^{Q_{i}^{*}} F(x) d x+\left[\kappa v_{i}^{1}-(1-\kappa) d_{i}-\kappa\left(p_{i}+t_{i}\right)\right] E(x) \\
& +\left\{v_{i}^{0}-\kappa v_{i}^{1}+(1-\kappa) d_{i}-\left[w_{i}+t_{i}+I_{i}+w_{i} E\left(\eta_{i}\right)\right]+\kappa\left(p_{i}+t_{i}\right)\right\} Q_{i}^{*}
\end{aligned}
$$

Moreover, the expected profit of the supplier can be expressed as follows:

$$
\begin{aligned}
\pi^{s} & =E\left[\left(w_{i}-c_{i}^{p}\right) Q_{i}^{*}+\kappa \max \left(x-Q_{i}^{*}, 0\right)\left(p_{i}-c_{i}^{r}\right)\right] \\
& \left.==\left(w_{i}-c_{i}^{p}\right) Q_{i}^{*}+\kappa\left[E(x)+\int_{0}^{Q_{i}^{*}} F(x) d x-Q_{i}^{*}\right]\left(p_{i}-c_{i}^{r}\right)\right]
\end{aligned}
$$


This is an Accepted Manuscript of an article published by Taylor \& Francis in International Journal of Production Research on 19 July 2018, available online: http://www.tandfonline.com/10.1080/00207543.2018.1495853.

\subsection{Sensitivity to critical ratio}

\subsubsection{Sensitivity to changes in $v_{i}^{1}$}

Proposition 2. The higher delay cost of good $i$ is, the more the purchaser would store in advance.

Proof: The numerator of the derivative of $Q_{i}^{*}$ with respect to $v_{i}^{1}$ is:

$$
-\frac{1}{f\left(Q_{i}^{*}\right)} \times \frac{\kappa\left(\theta_{p}-s_{i}\right)}{\left(\gamma_{i}+\kappa \theta_{r}-s_{i}\right)^{2}}
$$

We know that $f\left(Q_{i}^{*}\right)>0$ and $\theta_{p}-s_{i}>0$. According to the assumption, expression (8) will always be negative. As $v_{i}^{1}$ decreases, the prepositioned amount of good $i$ will increase. Smaller $v_{i}^{1}$ means that the value loss caused by delay is higher.

\subsubsection{Sensitivity to changes in shortage penalty cost $\left(d_{i}\right)$}

Proposition 3. The higher the shortage penalty cost is, the more the prepositioned inventory would be.

Proof: The numerator of the derivative of $Q_{i}^{*}$ with respect to $d_{i}$ is:

$$
\frac{1}{f\left(Q_{i}^{*}\right)} \times \frac{(1-\kappa)\left(\theta_{p}-s_{i}\right)}{\left(\gamma_{i}+\kappa \theta_{r}-s_{i}\right)^{2}}
$$

Since $f\left(Q_{i}^{*}\right), 1-\kappa$ and $\theta_{p}-s_{i}>0$ are always positive, expression (9) is positive. As $d_{i}$ increases, the prepositioned inventory will also increase.

\subsubsection{Sensitivity to changes in the risk of supply shortage $(\kappa)$}

Proposition 4. The larger $\kappa$ is, the less the purchaser would store in advance.

Proof: The numerator of the derivative of $Q_{i}^{*}$ with respect to $\kappa$ is:

$$
\frac{1}{f\left(Q_{i}^{*}\right)} \times \frac{\left(\theta_{p}-s_{i}\right)\left(-v_{i}^{1}-d_{i}+\theta_{r}\right)}{\left(\gamma_{i}+\kappa \theta_{r}-s_{i}\right)^{2}}
$$

As $f\left(Q_{i}^{*}\right)>0, \theta_{p}-s_{i}>0$ and $v_{i}^{1}>\theta_{r}$, the sign of expression (10) is negative. If 
This is an Accepted Manuscript of an article published by Taylor \& Francis in International Journal of Production Research on 19 July 2018, available online: http://www.tandfonline.com/10.1080/00207543.2018.1495853.

$\kappa$ increases, the prepositioned amount $Q_{i}^{*}$ will be reduced.

\subsubsection{Sensitivity to changes in salvage value $\left(s_{i}\right)$}

Proposition 5. The less salvage value of unused supplies is, the less amount of relief good $i$ is stored.

Proof: The numerator of the derivative of $Q_{i}^{*}$ with respect to $s_{i}$ is:

$$
\frac{1}{f\left(Q_{i}^{*}\right)} \times \frac{\gamma_{i}+\kappa \theta_{r}-\theta_{p}}{\left(\gamma_{i}+\kappa \theta_{r}-s_{i}\right)^{2}}
$$

As we know, $f\left(Q_{i}^{*}\right)>0$ and $\theta_{p}-\kappa \theta_{r}<\gamma_{i}$. Based on these assumptions, the sign of expression (11) will always be nonnegative.

\subsubsection{Sensitivity to changes in expected perishable rate $\left(E\left(\eta_{i}\right)\right)$}

Proposition 6. If one relief item is expected to be more perishable, the prepositioned inventory would be less.

Proof: The numerator of the derivative of $Q_{i}^{*}$ with respect to $E\left(\eta_{i}\right)$ is:

$$
-\frac{1}{f\left(Q_{i}^{*}\right)} \times \frac{w_{i}}{\gamma_{i}+\kappa \theta_{r}-s_{i}}
$$

As we know, $f\left(Q_{i}^{*}\right)>0, w_{i}>0$, and $\gamma_{i}+\kappa \theta_{r}-s_{i}>0$. It is obvious that expression (12) will always be negative. As $E\left(\eta_{i}\right)$ increases, $Q_{i}^{*}$ will decrease.

\subsection{Sensitivity to changes in the unit inventory cost $\left(I_{i}\right)$}

Proposition 7. As $I_{i}$ increases, the ex ante order quantity $Q_{i}^{*}$ would be reduced.

Proof: The numerator of the derivative of $Q_{i}^{*}$ with respect to $I_{i}$ is:

$$
-\frac{1}{f\left(Q_{i}^{*}\right)} \times \frac{1}{\gamma_{i}+\kappa \theta_{r}-s_{i}}
$$

As $f\left(Q_{i}^{*}\right)>0$, and $\gamma_{i}+\kappa \theta_{r}-s_{i}>0$, based on these assumptions, expression (13) will always be negative. 


\subsubsection{Sensitivity to changes in the reactive price $\left(p_{i}\right)$}

Proposition 8. As $p_{i}$ increases, the proactive inventory will also increase.

Proof: The numerator of the derivative of $Q_{i}^{*}$ with respect to $p_{i}$ is:

$$
\frac{1}{f\left(Q_{i}^{*}\right)} \times \frac{\kappa\left(\theta_{p}-s_{i}\right)}{\left(\gamma_{i}+\kappa \theta_{r}-s_{i}\right)^{2}}
$$

As $f\left(Q_{i}^{*}\right), \kappa$ and $\theta_{p}-s_{i}$ are positive, it easy to obtain that expression (14) will be positive.

\section{Outsourcing strategies}

In this section, we consider the situations of outsourcing. The buyer purchases for relief commodities. The inventory and distribution processes could be outsourced to the suppliers. Since an integrated disaster relief approach compromises both preparation and immediate response, the buyers can choose outsourcing options between proactive decision and reactive response. In the following part, we will analyze these two situations respectively.

\subsection{The scenario of proactive outsourcing response}

When the pre-disaster inventory is outsourced, government or NPOs pay $w_{i}^{\text {out }}$ for one unit of item $i$ and the supplier provides the service of inventory and distribution. To ensure the efficiency and effectiveness of outsourcing, the cost of supervision should be paid, which is denoted as $\beta_{i}$. With outsourcing, the unit cost for government or NPOs is $w_{i}^{\text {out }}+\beta_{i}$. We assume $w_{i}<w_{i}^{\text {out }}$, since the main goal of the third-party companies is to benefit from outsourcing. As for the private companies, the unit profit of $Q_{i}$ is $w_{i}^{\text {out }}-\left(c_{i}^{p}+I_{i}^{\text {out }}+t_{i}^{\text {out }}\right)$, where $I_{i}^{\text {out }}$ and $t_{i}^{\text {out }}$ are the inventory cost and shipping cost respectively. As the third party companies always have relatively high turnover rate, thus the cost of deterioration is not take into consideration. The purchaser's expected value can be expressed as follows:

$$
\begin{aligned}
\max _{Q_{i}^{p}} E(\pi) & =E\left[v_{i}^{0} \min \left(x, Q_{i}^{p}\right)+\kappa v_{i}^{1} \max \left(x-Q_{i}^{p}, 0\right)-(1-\kappa) d_{i} \max \left(x-Q_{i}^{p}, 0\right)\right. \\
& +s_{i} \max \left(Q_{i}^{p}-x, 0\right)-\left(w_{i}^{\text {out }}+\beta_{i}\right) Q_{i}^{p}-\kappa\left(p_{i}+t_{i}\right) \max \left(x-Q_{i}^{p}, 0\right)
\end{aligned}
$$

After some transformation, we can get 


$$
\begin{aligned}
\max _{Q_{i}^{p}} E(\pi) & =\left[-v_{i}^{0}+\kappa v_{i}^{1}-(1-\kappa) d_{i}+s_{i}-\kappa\left(p_{i}+t_{i}\right)\right] \int_{0}^{Q_{i}^{p}} F(x) d x+\left[\kappa v_{i}^{1}-(1-\kappa) d_{i}-\kappa\left(p_{i}+t_{i}\right)\right] E(x) \\
& +\left[v_{i}^{0}-\kappa v_{i}^{1}+(1-\kappa) d_{i}-\left(w_{i}^{\text {out }}+\beta_{i}\right)+\kappa\left(p_{i}+t_{i}\right)\right] Q_{i}^{p}
\end{aligned}
$$

Similarly, with the application of algebra, it is easy to obtain:

$$
Q_{i}^{p^{*}}= \begin{cases}0 & \text { if }\left(w_{i}^{\text {out }}+\beta_{i}\right)-\kappa \theta_{r} \geq \gamma_{i} \\ F^{-1}\left(\frac{\gamma_{i}+\kappa \theta_{r}-\left(w_{i}^{\text {out }}+\beta_{i}\right)}{\gamma_{i}+\kappa \theta_{r}-s_{i}}\right) & \text { if }\left(w_{i}^{\text {out }}+\beta_{i}\right)-\kappa \theta_{r}<\gamma_{i}\end{cases}
$$

As what mentioned above, we assume $\left(w_{i}^{\text {out }}+\beta_{i}\right)-\kappa \theta_{r}<\gamma_{i}$. The optimal stock quantity of good $i$ in this scenario is as follows:

$$
Q_{i}^{p^{*}}=F^{-1}\left(\frac{\gamma_{i}+\kappa \theta_{r}-\left(w_{i}^{\text {out }}+\beta_{i}\right)}{\gamma_{i}+\kappa \theta_{r}-s_{i}}\right)
$$

The expected value of the purchaser is:

$$
\begin{aligned}
\mathrm{V}\left(Q_{i}^{p^{*}}\right) & =\left[-v_{i}^{0}+\kappa v_{i}^{1}-(1-\kappa) d_{i}+s_{i}-\kappa\left(p_{i}+t_{i}\right)\right] \int_{0}^{Q_{i}^{p^{*}}} F(x) d x+\left[\kappa v_{i}^{1}-(1-\kappa) d_{i}-\kappa\left(p_{i}+t_{i}\right)\right] E(x) \\
& +\left[v_{i}^{0}-\kappa v_{i}^{1}+(1-\kappa) d_{i}-\left(w_{i}^{\text {out }}+\beta_{i}\right)+\kappa\left(p_{i}+t_{i}\right)\right] Q_{i}^{p^{*}}
\end{aligned}
$$

The expected profit of the supplier is:

$$
\begin{aligned}
\pi^{\text {sp }} & =\left(w_{i}^{\text {out }}-t_{i}^{\text {out }}-I_{i}^{\text {out }}-c_{i}^{p}\right) Q_{i}^{p^{*}}+\kappa \max \left(x-Q_{i}^{p^{*}}, 0\right)\left(p_{i}-c_{i}^{r}\right) \\
& =\left(w_{i}^{\text {out }}-t_{i}^{\text {out }}-I_{i}^{\text {out }}-c_{i}^{p}\right) Q_{i}^{p^{*}}+\kappa\left[E(x)+\int_{0}^{Q_{i}^{p^{*}}} F(x) d x-Q_{i}^{p^{*}}\right]\left(p_{i}-c_{i}^{r}\right)
\end{aligned}
$$

Proposition 9.

(1) The relationship between the optimal quantities $Q_{i}^{*}$ and $Q_{i}^{p^{*}}$ is as follows:

$$
\left\{\begin{array}{l}
Q_{i}^{p^{*}}<Q_{i}^{*} \text { if } w_{i}^{\text {out }}+\beta_{i}>w_{i}+t_{i}+I_{i}+w_{i} E\left(\eta_{i}\right) \\
Q_{i}^{p^{*}} \geq Q_{i}^{*} \text { if } w_{i}^{\text {out }}+\beta_{i} \leq w_{i}+t_{i}+I_{i}+w_{i} E\left(\eta_{i}\right)
\end{array}\right.
$$

(2) The profit of supplier and purchaser depends much on the expected perishable rate and monitoring cost. When the expected perishable rate $E\left(\eta_{i}\right)$ is relatively large, the efficiency of a relief supply chain is improved in views of outsourcing. When the expected perishable rate is relatively low, a better strategy for government or NPOs is to taking the proactive insourcing approach.

(3) When the monitoring cost $\beta_{i}$ is high, the benefit of government or NPOs cannot be improved simultaneously with outsourcing approach. While, with a relatively low $\beta_{i}$, outsourcing can improve the efficiency of relief supply chain.

\section{Proof. See Appendix A}


This is an Accepted Manuscript of an article published by Taylor \& Francis in International Journal of Production Research on 19 July 2018, available online: http://www.tandfonline.com/10.1080/00207543.2018.1495853.

\subsection{The scenario of reactive outsourcing response.}

In this scenario, after a disaster strikes, the government or NPOs outsource the process of real-time response. The buyers purchase and the suppliers distribute the critical needs to the victims. The buyer pays the unit price of $p_{i}^{\text {out }}$ for $q_{i}$ and we assume that $p_{i}^{\text {out }}>p_{i}$. As for the supplier, the unit cost is $c_{i}^{r}+t_{i}^{\text {out }}$, where $t_{i}^{\text {out }}$ is the distribution cost. The expected value of the purchaser is:

$$
\begin{aligned}
\max _{Q_{i}^{r}} E(\pi)= & E\left[v_{i}^{0} \min \left(x, Q_{i}^{r}\right)+\kappa v_{i}^{2} \max \left(x-Q_{i}^{r}, 0\right)-(1-\kappa) d_{i} \max \left(x-Q_{i}^{r}, 0\right)\right. \\
& \left.+s_{i} \max \left(Q_{i}^{r}-x, 0\right)-\left(w_{i}+t_{i}+I_{i}+w_{i} \eta_{i}\right) Q_{i}^{r}-\kappa\left(p_{i}^{\text {out }}+\beta_{i}\right) \max \left(x-Q_{i}^{r}, 0\right)\right]
\end{aligned}
$$

Through transforming, expression (20) can be given as:

$$
\begin{aligned}
\max _{Q_{i}^{r}} E(\pi)= & {\left[-v_{i}^{0}+\kappa v_{i}^{2}-(1-\kappa) d_{i}+s_{i}-\kappa\left(p_{i}^{\text {out }}+\beta_{i}\right)\right] \int_{0}^{Q_{i}^{r}} F(x) d x+\left[\kappa v_{i}^{2}-(1-\kappa) d_{i}-\kappa\left(p_{i}^{\text {out }}+\beta_{i}\right)\right] E(x) } \\
& +\left\{v_{i}^{0}-\kappa v_{i}^{2}+(1-\kappa) d_{i}-\left[w_{i}+t_{i}+I_{i}+w_{i} E\left(\eta_{i}\right)\right]+\kappa\left(p_{i}^{\text {out }}+\beta_{i}\right)\right\} Q_{i}^{r}
\end{aligned}
$$

With the application of algebra, we can obtain:

$$
Q_{i}^{r *}= \begin{cases}0 & \text { if } \theta_{p}-\kappa\left(p_{i}^{\text {out }}+\beta_{i}\right) \geq \delta_{i} \\ F^{-1}\left(\frac{\delta_{i}+\kappa\left(p_{i}^{\text {out }}+\beta_{i}\right)-\theta_{p}}{\delta_{i}+\kappa\left(p_{i}^{\text {out }}+\beta_{i}\right)-s_{i}}\right) & \text { if } \theta_{p}-\kappa\left(p_{i}^{\text {out }}+\beta_{i}\right)<\delta_{i}\end{cases}
$$

Where $\delta_{i}=v_{i}^{0}-\kappa v_{i}^{2}+(1-\kappa) d_{i}$. Similar to what mentioned above, we assume $\theta_{p}-\kappa\left(p_{i}^{\text {out }}+\beta_{i}\right)<\delta_{i}$. And the optimal quantity $Q_{i}^{r *}$ is expressed as follows:

$$
Q_{i}^{r *}=F^{-1}\left(\frac{\delta_{i}+\kappa\left(p_{i}^{\text {out }}+\beta_{i}\right)-\theta_{p}}{\delta_{i}+\kappa\left(p_{i}^{\text {out }}+\beta_{i}\right)-s_{i}}\right)
$$

The expected social value is:

$$
\begin{aligned}
\mathrm{V}\left(Q_{i}^{r^{*}}\right) & =\left[-v_{i}^{0}+\kappa v_{i}^{2}-(1-\kappa) d_{i}+s_{i}-\kappa\left(p_{i}^{\text {out }}+\beta_{i}\right)\right] \int_{0}^{Q_{i}^{r^{*}}} F(x) d x+\left[\kappa v_{i}^{2}-(1-\kappa) d_{i}-\kappa\left(p_{i}^{\text {out }}+\beta_{i}\right)\right] E(x) \\
& +\left[v_{i}^{0}-\kappa v_{i}^{2}+(1-\kappa) d_{i}-\left(w_{i}+t_{i}+I_{i}+w_{i} \eta_{i}\right)+\kappa\left(p_{i}^{\text {out }}+\beta_{i}\right)\right] Q_{i}^{r^{*}}
\end{aligned}
$$

The expected profit of supplier is:

$$
\begin{aligned}
\pi^{\text {sr }} & =\left(w_{i}-c_{i}^{p}\right) Q_{i}^{r^{*}}+\kappa \max \left(x-Q_{i}^{r^{*}}, 0\right)\left(p_{i}^{\text {out }}-t_{i}^{\text {out }}-c_{i}^{r}\right) \\
& \left.=\left(w_{i}-c_{i}^{p}\right) Q_{i}^{r^{*}}+\left[E(x)+\int_{0}^{Q_{i}^{* *}} F(x) d x-Q_{i}^{r^{*}}\right]\left(p_{i}^{\text {out }}-t_{i}^{\text {out }}-c_{i}^{r}\right)\right]
\end{aligned}
$$

Proposition 10.

(1) The relationship between the optimal quantities $Q_{i}^{*}$ and $Q_{i}^{r *}$ is as follows:

$$
\left\{\begin{array}{l}
Q_{i}^{r^{*}}<Q_{i}^{*} \text { if }\left(p_{i}^{\text {out }}+\beta_{i}\right)-\left(p_{i}+t_{i}\right)<v_{i}^{2}-v_{i}^{1} \\
Q_{i}^{r^{*}} \geq Q_{i}^{*} \text { if }\left(p_{i}^{\text {out }}+\beta_{i}\right)-\left(p_{i}+t_{i}\right) \geq v_{i}^{2}-v_{i}^{1}
\end{array}\right.
$$


This is an Accepted Manuscript of an article published by Taylor \& Francis in International Journal of Production Research on 19 July 2018, available online: http://www.tandfonline.com/10.1080/00207543.2018.1495853.

(2) when monitoring cost is relatively small, or in other words the quality of a certain relief material is easy to be monitored, outsourcing will possibly improve revenues of the third-party companies, the government and NPOs.

(3) When monitoring cost is high, it seems impossible to improve the expected benefits of the supplier and purchaser simultaneously through outsourcing.

Proof. See Appendix A

\section{Discussions and conclusions}

By a two-stage coordinated approach, this paper examines the optimal amount of proactive inventory for a certain relief item with and without outsourcing approach. We find that when and only when the difference between the proactive cost and the reactive cost is lower than the expected delay and shortage cost, the purchasers would choose to store relief supplies in advance, to enable a quick response; otherwise, it is much better to take reactive approach. In the basic model, the results show that the delay cost, shortage penalty cost, risk of supply shortage, salvage value, expected perishable rate, unit inventory cost and reactive price have significant impacts on the optimal amount of proactive inventory.

In the case of proactive outsourcing strategy, social efficiency improvement mainly depends on the expected perishable rates and the monitoring costs. When the expected perishable rate is high or monitoring cost is low, the efficiency of relief supply chain can be improved through outsourcing. Otherwise, a better strategy for governments or NPOs is to take the insourcing approach.

As for reactive outsourcing strategy, the monitoring cost has played an important role. When the monitoring cost is small, in other words, the quality of a certain relief commodity is easy to monitor, outsourcing can possibly improve the revenues of the third-party companies, the government or NPOs. However, when the monitoring cost is high, it seems impossible to improve the expected benefits of the supplier and the purchaser simultaneously.

The analysis gives out several recommendations. First, the inventory strategies differ by types of relief commodities. The optimal pre-disaster order quantity of material inventory depends much on its expected perishable rate and other characteristics. Second, in some specific scenarios, the benefits of all members and the efficiency of relief supply chain can be simultaneously improved by outsourcing. 
This is an Accepted Manuscript of an article published by Taylor \& Francis in International Journal of Production Research on 19 July 2018, available online: http://www.tandfonline.com/10.1080/00207543.2018.1495853.

The third-party companies have the motivation to take part in the relief supply chain and therefore could play an important role to improve the efficiency of humanitarian relief. Finally, as for governments and NPOs, in terms of unperishable item the optimal response is to combine proactive outsourcing approach and reactive outsourcing strategy. In terms of imperishable item, the optimal response method is to choose proactive insourcing approach and reactive outsourcing strategy. In addition, the insourcing approach is much better for some materials whose monitoring cost is high.

All in all, this paper compares the optimal prepositioned quantity of a certain good, with and without outsourcing and provides some insights about the relief material inventory system for the government or NPOs. There is still much room for further improvement, such as introducing option contract into the model. The combination of option contract and outsourcing would be an interesting topic for further research. 


\section{Appendix A}

\section{Proof of proposition 9}

we assume that the unit revenue from re-purchasing and real-time purchasing of the supplier is same in the insourcing approach, namely $w_{i}-c_{i}^{p}=p_{i}-c_{i}^{r}$. Moreover, for better comparison, we assume $w_{i}^{\text {out }}-t_{i}^{\text {out }}-I_{i}^{\text {out }}=w_{i}+\rho_{i}$, where $\rho_{i}$ is a small number large than zero. This assumption matches the reality as the target of the private enterprises is to make profit.

When $w_{i}^{\text {out }}+\beta_{i}>w_{i}+t_{i}+I_{i}+w_{i} E\left(\eta_{i}\right) \quad$ we can obtain:

$$
Q_{i}^{p^{*}}=F^{-1}\left(\frac{\gamma_{i}+\kappa \theta_{r}-\left(w_{i}^{\text {out }}+\beta_{i}\right)}{\gamma_{i}+\kappa \theta_{r}-s_{i}}\right)<Q_{i}^{*}=F^{-1}\left(\frac{\gamma_{i}+\kappa \theta_{r}-\theta_{p}}{\gamma_{i}+\kappa \theta_{r}-s_{i}}\right)
$$

When $w_{i}^{\text {out }}+\beta_{i} \leq w_{i}+t_{i}+I_{i}+w_{i} E\left(\eta_{i}\right)$, we have:

$$
Q_{i}^{p^{*}}=F^{-1}\left(\frac{\gamma_{i}+\kappa \theta_{r}-\left(w_{i}^{\text {out }}+\beta_{i}\right)}{\gamma_{i}+\kappa \theta_{r}-s_{i}}\right) \geq Q_{i}^{*}=F^{-1}\left(\frac{\gamma_{i}+\kappa \theta_{r}-\theta_{p}}{\gamma_{i}+\kappa \theta_{r}-s_{i}}\right)
$$

It is hard to evaluate the relationship between $\mathrm{V}\left(Q_{i}^{*}\right)$ and $\mathrm{V}\left(Q_{i}^{p^{*}}\right)$ in this form directly. For better comparison, we let $Q_{i}^{p}=Q_{i}^{*}$, and thus the optimal social value without outsourcing is as follows:

$$
\begin{aligned}
\mathrm{V}\left(Q_{i}^{*}\right) & =\left[-v_{i}^{0}+\kappa v_{i}^{1}-(1-\kappa) d_{i}+s_{i}-\kappa\left(p_{i}+t_{i}\right)\right] \int_{0}^{Q_{i}^{*}} F(x) d x+\left[\kappa v_{i}^{1}-(1-\kappa) d_{i}-\kappa\left(p_{i}+t_{i}\right)\right] E(x) \\
& +\left\{v_{i}^{0}-\kappa v_{i}^{1}+(1-\kappa) d_{i}-\left[w_{i}+t_{i}+I_{i}+w_{i} E\left(\eta_{i}\right)\right]+\kappa\left(p_{i}+t_{i}\right)\right\} Q_{i}^{*}
\end{aligned}
$$

When $Q_{i}^{p}=Q_{i}^{*}$, the social value of proactive outsourcing strategy is:

$$
\begin{aligned}
\mathrm{V}\left(Q_{i}^{p}\right) & =\left[-v_{i}^{0}+\kappa v_{i}^{1}-(1-\kappa) d_{i}+s_{i}-\kappa\left(p_{i}+t_{i}\right)\right] \int_{0}^{Q_{i}^{*}} F(x) d x+\left[\kappa v_{i}^{1}-(1-\kappa) d_{i}-\kappa\left(p_{i}+t_{i}\right)\right] E(x) \\
& +\left[v_{i}^{0}-\kappa v_{i}^{1}+(1-\kappa) d_{i}-\left(w_{i}^{\text {out }}+\beta_{i}\right)+\kappa\left(p_{i}+t_{i}\right)\right] Q_{i}^{*}
\end{aligned}
$$

And we can obtain:

$$
\Delta V^{1}=\mathrm{V}\left(Q_{i}^{p}\right)-\mathrm{V}\left(Q_{i}^{*}\right)=\left\{\left[w_{i}+t_{i}+I_{i}+w_{i} E\left(\eta_{i}\right)\right]-\left(w_{i}^{\text {out }}+\beta_{i}\right)\right\} Q_{i}^{*}
$$

If the condition $w_{i}^{\text {out }}+\beta_{i} \leq w_{i}+t_{i}+I_{i}+w_{i} E\left(\eta_{i}\right)$ is met, we can easily get $\Delta V^{1} \geq 0$.

Since it has been proved that $Q_{i}^{p^{*}}$ is the optimal stock quantity of solving the maximization problem of $\mathrm{E}\left[\pi\left(Q_{i}^{p}\right)\right]$, there is $\mathrm{V}\left(Q_{i}^{p^{*}}\right) \geq \mathrm{V}\left(Q_{i}^{p}=Q_{i}^{*}\right) \geq \mathrm{V}\left(Q_{i}^{*}\right)$.

Through the analysis, when $\beta_{i}$ is small enough or $\eta_{i}$ is large enough, meaning 
the condition $w_{i}^{\text {out }}+\beta_{i} \leq w_{i}+t_{i}+I_{i}+w_{i} E\left(\eta_{i}\right)$ could be satisfied, the social efficiency could be improved. Next, we will analyze the profit of the supplier under this situation. As $w_{i}^{\text {out }}+\beta_{i} \leq w_{i}+t_{i}+I_{i}+w_{i} E\left(\eta_{i}\right)$, it can easily obtain $Q_{i}^{p^{*}} \geq Q_{i}^{*}$, The difference in supplier's profit is:

$$
\begin{aligned}
\Delta \pi^{s 1}=\pi^{s p}-\pi^{s} & \left.=\left(w_{i}+\rho_{i}-c_{i}^{p}\right) Q_{i}^{p^{*}}+\kappa\left[E(x)+\int_{0}^{Q_{i}^{p^{*}}} F(x) d x-Q_{i}^{p^{*}}\right]\left(p_{i}-c_{i}^{r}\right)\right] \\
& \left.-\left(w_{i}-c_{i}^{p}\right) Q_{i}^{*}-\kappa\left[E(x)+\int_{0}^{Q_{i}^{*}} F(x) d x-Q_{i}^{*}\right]\left(p_{i}-c_{i}^{r}\right)\right] \\
& =\rho_{i} Q_{i}^{p^{*}}+\int_{Q_{i}^{*}}^{Q_{p^{*}}^{*}} F(x) d x\left(p_{i}-c_{i}^{r}\right)
\end{aligned}
$$

As $\rho_{i}$ and $Q_{i}^{p^{*}}$ is positive, additionally $Q_{i}^{p^{*}} \geq Q_{i}^{*}$ and $\left(p_{i}-c_{i}^{r}\right)>0$, the sign of $\Delta \pi^{s 1}$ is positive. Therefore, the supplier also can get better.

\section{Proof of proposition 10}

Similarly, for better comparison, we assume $p_{i}^{\text {out }}-t_{i}^{\text {out }}=p_{i}+\mu_{i}$, where $\mu_{i}$ is a small number large than zero, and $w_{i}-c_{i}^{p}=p_{i}-c_{i}^{r}$.

Through comparison, the results show that When $\left(p_{i}^{\text {out }}+\beta_{i}\right)-\left(p_{i}+t_{i}\right)<v_{i}^{2}-v_{i}^{1}$, we have the following relationship between $Q_{i}^{*}$ and $Q_{i}^{r *}$.

$$
Q_{i}^{r^{*}}=F^{-1}\left(\frac{\delta_{i}+\kappa\left(p_{i}^{\text {out }}+\beta_{i}\right)-\theta_{p}}{\delta_{i}+\kappa\left(p_{i}^{\text {out }}+\beta_{i}\right)-s_{i}}\right)<Q_{i}^{*}=F^{-1}\left(\frac{\gamma_{i}+\kappa \theta_{r}-\theta_{p}}{\gamma_{i}+\kappa \theta_{r}-s_{i}}\right)
$$

If $\left(p_{i}^{\text {out }}+\beta_{i}\right)-\left(p_{i}+t_{i}\right) \geq v_{i}^{2}-v_{i}^{1}$, we have:

$$
Q_{i}^{r^{*}}=F^{-1}\left(\frac{\delta_{i}+\kappa\left(p_{i}^{\text {out }}+\beta_{i}\right)-\theta_{p}}{\delta_{i}+\kappa\left(p_{i}^{\text {out }}+\beta_{i}\right)-s_{i}}\right) \geq Q_{i}^{*}=F^{-1}\left(\frac{\gamma_{i}+\kappa \theta_{r}-\theta_{p}}{\gamma_{i}+\kappa \theta_{r}-s_{i}}\right)
$$

In this case, it also hard to compare the relationship between $\mathrm{V}\left(Q_{i}^{*}\right)$ and $\mathrm{V}\left(Q_{i}^{r *}\right)$ directly. Similarly, we let $Q_{i}^{r}=Q_{i}^{*}$, and thus the social value with reactive outsourcing response is as follows:

$$
\begin{aligned}
\mathrm{V}\left(Q_{i}^{r}\right) & =\left[-v_{i}^{0}+\kappa v_{i}^{2}-(1-\kappa) d_{i}+s_{i}-\kappa\left(p_{i}^{\text {out }}+\beta_{i}\right)\right] \int_{0}^{Q_{i}^{*}} F(x) d x+\left[\kappa v_{i}^{2}-(1-\kappa) d_{i}-\kappa\left(p_{i}^{\text {out }}+\beta_{i}\right)\right] E(x) \\
& +\left\{v_{i}^{0}-\kappa v_{i}^{2}+(1-\kappa) d_{i}-\left[w_{i}+t_{i}+I_{i}+w_{i} E\left(\eta_{i}\right)\right]+\kappa\left(p_{i}^{\text {out }}+\beta_{i}\right)\right\} Q_{i}^{*}
\end{aligned}
$$

And we get:

$$
\Delta V^{2}=\mathrm{V}\left(Q_{i}^{r}\right)-\mathrm{V}\left(Q_{i}^{*}\right)=\kappa\left[\left(v_{i}^{2}-v_{i}^{1}\right)-\left[\left(p_{i}^{\text {out }}+\beta_{i}\right)-\left(p_{i}+t_{i}\right)\right] E\left[\max \left(x-Q_{i}^{*}, 0\right)\right]\right.
$$

As $\mathrm{E}\left[\max \left(x-Q_{i}^{*}, 0\right)>0\right]$, if $\left(p_{i}^{\text {out }}+\beta_{i}\right)-\left(p_{i}+t_{i}\right)<v_{i}^{2}-v_{i}^{1}$, we will have $\Delta V^{2}>0$.

Since it has been proved that $Q_{i}^{r *}$ is the optimal stock quantity of solving the 
This is an Accepted Manuscript of an article published by Taylor \& Francis in International Journal of Production Research on 19 July 2018, available online: http://www.tandfonline.com/10.1080/00207543.2018.1495853.

maximization problem of $E\left[\pi\left(Q_{i}^{r}\right)\right]$, there is $\mathrm{V}\left(Q_{i}^{r^{*}}\right) \geq \mathrm{V}\left(Q_{i}^{r}=Q_{i}^{*}\right) \geq \mathrm{V}\left(Q_{i}^{*}\right)$.

Through the analysis, we find when the monitoring cost $\beta_{i}$ is small enough, the social efficiency could be improved, thus we just analyze the profit of the supplier under this situation. As $\left(p_{i}^{\text {out }}+\beta_{i}\right)-\left(p_{i}+t_{i}\right)<v_{i}^{2}-v_{i}^{1}$, it can easily obtain $Q_{i}^{r^{*}}<Q_{i}^{*}$, The difference in supplier's profit is:

$$
\begin{aligned}
\Delta \pi^{s 2}=\pi^{s r}- & \left.\pi^{s}=\left(w_{i}-c_{i}^{p}\right) Q_{i}^{r^{*}}+\kappa\left[E(x)+\int_{0}^{Q_{i}^{r_{*}^{*}}} F(x) d x-Q_{i}^{r^{*}}\right]\left(p_{i}+\mu_{i}-c_{i}^{r}\right)\right] \\
& \left.-\left(w_{i}-c_{i}^{p}\right) Q_{i}^{*}-\kappa\left[E(x)+\int_{0}^{Q_{i}^{*}} F(x) d x-Q_{i}^{*}\right]\left(p_{i}-c_{i}^{r}\right)\right] \\
= & \kappa\left[E(x)+\int_{0}^{Q_{i}^{* *}} F(x) d x-Q_{i}^{r^{*}}\right] \mu_{i}-\kappa \int_{Q_{i}^{r^{*}}}^{Q_{i}^{*}} F(x) d x
\end{aligned}
$$

As the relationship between $\kappa\left[E(x)+\int_{0}^{Q_{i}^{r^{*}}} F(x) d x-Q_{i}^{r^{*}}\right] \mu_{i}$ and $\kappa \int_{Q_{i}^{r^{*}}}^{Q^{*}} F(x) d x$ is unclear. The sign of $\Delta \pi^{s 2}$ cannot be obtained according to the existing assumptions. 


\section{References}

Nagurney, A., M. Yu, and Q. Qiang. 2011. "Supply chain network design for critical needs with outsourcing.” Papers in Regional Science, 90(1):123-142.

Balcik, B., B. M. Beamon. 2008. "Facility location in humanitarian relief." International Journal of Logistics, 11(2): 101-121.

Barbarosoğlu, G., and Y. Arda. 2004. A two-stage stochastic programming framework for transportation planning in disaster response. Journal of the Operational Research Society, 55(1):43-53.

Beamon, B. M., and B. Balcik. 2008. "Performance measurement in humanitarian relief chains.” International Journal of Public Sector Management, 21(1): 4-25.

Beamon, B. M., and S. A. Kotleba. 2006. "Inventory modelling for complex emergencies in humanitarian relief operations.” International Journal of Logistics: Research and Applications, 9(1): 1-18.

Bottani, E., and A. Rizzi A. 2006. "A fuzzy TOPSIS methodology to support outsourcing of logistics services." Supply Chain Management: An International Journal, 11(4): 294-308.

Carbonnier, G. 2006. "Privatisation and outsourcing in wartime: the humanitarian challenges.” Disasters, 30(4): 402-416.

Chakravarty A K. 2011. "A contingent plan for disaster response.” International Journal of Production Economics 134(1):3-15.

Chakravarty, A. K. 2014. "Humanitarian relief chain: Rapid response under uncertainty." International Journal of Production Economics 151: 146-157.

Chavan M. 2017. "An appraisal of environment management systems: A competitive advantage for small businesses." Management of Environmental Quality An International Journal 16(5):444-463.

Cottam, H., M. Roe, and J. Challacombe. 2004. "Outsourcing of trucking activities by relief organisations.” Journal of Humanitarian Assistance 1(1).

Cruzcantillo Y., and A. Saleh. 2014. "A System Dynamics Approach to Humanitarian Logistics and the Transportation of Relief Supplies.” International Journal of System Dynamics Applications 3(1):96-126.

Da Costa, S. R. A., V. B. G. Campos, and R. A. de Mello Bandeira. 2012. "Supply chains in humanitarian operations: cases and analysis." Procedia-Social and Behavioral Sciences 54: 598-607.

Day, J. M., S. A. Melnyk, P. D. Larson, et al. 2012. "Humanitarian and disaster relief supply chains: a matter of life and death.” Journal of Supply Chain Management 48(2): 21-36.

Day, J. M. 2104. "Fostering emergent resilience: the complex adaptive supply network of disaster relief." International Journal of Production Research 52(7):1970-1988.

Dolgui, A., D. Ivanov, and B. Sokolov. 2017. "Ripple effect in the supply chain: an analysis and recent literature.” International Journal of Production Research 2017(3):1-17.

Duran, S., and M. A. Gutierrez. 2011. "Keskinocak P. Pre-positioning of emergency items for CARE international.” Interfaces 41(3): 223-237.

Gadde, L. E., and K. Hulthén. 2009. "Improving logistics outsourcing through increasing buyer-provider interaction.” Industrial Marketing Management 38(6): 633-640.

Gil, J. C. S., and S. Mcneil. 2015. "Supply Chain Outsourcing in Response to 
Manmade and Natural Disasters in Colombia, a Humanitarian Logistics Perspective.” Procedia Engineering 107(3):110-121.

Grossman, G. M., and E. Helpman. 2005. "Outsourcing in a Global Economy.” Review of Economic Studies 72(1):135-159.

Kovács, G., and K. M. Spens. 2007. "Humanitarian logistics in disaster relief operations." International Journal of Physical Distribution \& Logistics Management 37(2):99-114.

Hansen, C., C. Mena, and H. Skipworth. 2016. "Exploring political risk in offshoring engagements.” International Journal of Production Research 55(7):2051-2067.

Hsiao, H. I., R. G. M. Kemp, J.G.A.J. van der Vorst, et al. 2010. A classification of logistic outsourcing levels and their impact on service performance: Evidence from the food processing industry. International Journal of Production Economics 124(1):75-86.

Holguín-Veras, J., N. Pérez, S. Ukkusuri, et al. 2007. Emergency logistics issues affecting the response to Katrina: a synthesis and preliminary suggestions for improvement. Transportation Research Record: Journal of the Transportation Research Board (2022): 76-82.

Hong, J., A. T. H. Chin, and B. Liu. 2004. Logistics outsourcing by manufacturers in China: a survey of the industry. Transportation journal: 17-25.

Horwitz, S. 2009. Wal-Mart to the rescue: private enterprise's response to Hurricane Katrina. The Independent Review 13(4): 511-528.

Iakovou, E., D. Vlachos, C. Keramydas, et al. (2014). Dual sourcing for mitigating humanitarian supply chain disruptions. Journal of Humanitarian Logistics and Supply Chain Management 4(2): 245-264.

Ivanov, D., B. Sokolov, and A. Dolgui. 2014. The Ripple effect in supply chains: trade-off 'efficiency-flexibility-resilience' in disruption management. International Journal of Production Research 52(7):2154-2172.

Ivanov, D., B. Sokolov, I. Solovyeva, et al. 2016. Dynamic recovery policies for time-critical supply chains under conditions of ripple effect. International Journal of Production Research 54(23):7245-7258.

König, A, S. Spinler. 2016. The effect of logistics outsourcing on the supply chain vulnerability of shippers: Development of a conceptual risk management framework. The International Journal of Logistics Management 27(1): 122-141.

Kunz, N., G. Reiner, and S. Gold. 2014. Investing in disaster management capabilities versus pre-positioning inventory: a new approach to disaster preparedness. International Journal of Production Economics 157: 261-272.

Lieb, R. C., and H. L. Randall. 1999. 1997 CEO Perspectives on the Current Status and Future Prospects of the Third Party Logistics Industry in the United States. Transportation Journal (American Society of Transportation \& Log 38(3):28-41.

Liang, L., X. Wang, and J. Gao. 2012. An option contract pricing model of relief material supply chain. Omega 40(5):594-600.

Lin Moe, T., F. Gehbauer, S. Senitz, et al. 2007. Balanced scorecard for natural disaster management projects. Disaster Prevention and Management: An International Journal 16(5): 785-806.

Lodree, E. J., K. N. Ballard, and C. H. Song. 2012. Pre-positioning hurricane supplies in a commercial supply chain. Socio-Economic Planning Sciences 46(4), 291-305.

Manopiniwes, W., and T. Irohara. 2016. Stochastic optimisation model for integrated decisions on relief supply chains: preparedness for disaster response. International Journal of Production Research 55(4), 979-996.

Nagurney, A., M. Yu, and Q. Qiang. 2011. Supply chain network design for critical 
needs with outsourcing. Papers in Regional Science 90(1): 123-142.

Naor, M., A. Dey, S. M. Goldstein, et al. 2017. Civilian-military pooling of health care resources in Haiti: a theory of complementarities perspective. International Journal of Production Research (2):1-17.

Ransikarbum, K., and S. J. Mason. 2014. Multiple-objective analysis of integrated relief supply and network restoration in humanitarian logistics operations. International Journal of Production Research (1):49-68.

Razzaque, M. A., and C. C. Sheng. 1998. Outsourcing of logistics functions: a literature survey. International Journal of Physical Distribution \& Logistics Management 28(2):89-107.

Rezaei-Malek, M., R. Tavakkoli-Moghaddam, B. Zahiri, et al. 2016. An interactive approach for designing a robust disaster relief logistics network with perishable commodities. Computers \& Industrial Engineering 94:201-215.

Sohail, M. S., and A. S. Sohal. 2003. The use of third party logistics services: a Malaysian perspective. Technovation 23(5):401-408.

Thomas, A. S., and L. R. Kopczak. 2005. From logistics to supply chain management: the path forward in the humanitarian sector. Fritz Institute 15: 1-15.

UNISDR. 2016. United Nations Office for Disaster Risk Reduction. Comparing present to past. Retrieved on February 29, 2016.http://www.unisdr.org/files/47804_2015disastertrendsinfographic.pdf.

Wang, X., F. Li, L. Liang, et al. 2015. Pre-purchasing with option contract and coordination in a relief supply chain. International Journal of Production Economics 167: 170-176.

Wang, X., and Z. Huang. 2014. Outsourcing logistic service to a private enterprise in a relief supply chain. International Conference on Service Systems and Service Management IEEE:1-5.

Wang, X., Y. Wu, L. Liang, et al. 2016. Service outsourcing and disaster response methods in a relief supply chain. Annals of Operations Research 240(2):471-487.

Wei, S. L. 2000. A lemon market? An incentive scheme to induce truth-telling in third party logistics providers. European Journal of Operational Research 125(3):519-525.

Yadavalli ,V. S. S., D. K. Sundar, S. Udayabaskaran. 2015. Two substitutable perishable product disaster inventory systems. Annals of Operations Research 233(1):517-534.

Yang, F., Q. Yuan, S. Du, et al. 2014. Reserving relief supplies for earthquake: a multi-attribute decision making of China Red Cross. Annals of Operations Research $1-27$.

Yang, Q., X. Zhao, H. Y. J. Yeung, et al. 2016. Improving logistics outsourcing performance through transactional and relational mechanisms under transaction uncertainties: Evidence from China, International Journal of Production Economics 175: 12-23. 